\title{
AFFORDANCES NA INTERAÇÃO ONLINE DE APRENDIZES DE INGLÊS NA MODALIDADE EDUCAÇÃO A DISTÂNCIA
}

\author{
Andreia Turolo ${ }^{1^{\star}}$ \\ ${ }^{1}$ Universidade Federal do Ceará, Fortaleza, CE, Brasil
}

\begin{abstract}
Resumo
O objetivo principal desta pesquisa foi descrever os mecanismos de engajamento com affordances que ajudam a sustentar a interação interpessoal escrita em fóruns de discussão em um ambiente virtual de aprendizagem de inglês como língua estrangeira. A noção de affordance foi discutida neste trabalho em três dimensões: (i) a ambiental, (ii) a tecnológica e (iii) a linguística, associando a esta última uma teoria pragmática (GREENO, 1994; VAN LIER, 2000; LAMY \& HAMPEL, 2007). As descobertas evidenciaram que affordances tecnológicos e ambientais contribuíram para a construção da presença no ambiente e da comunidade de aprendizagem. Evidenciou-se que novas formas de interação online apontam para novas formas de aprender uma língua, principalmente pelo movimento de relexicalização e preenchimento de lacunas.

Palavras-chave: Affordances; Interação Online; Aprendizagem de Línguas; Educação a Distância.
\end{abstract}

\section{AFFORDANCES IN THE ONLINE INTERACTION OF ENGLISH LANGUAGE LEARNERS IN DISTANCE EDUCATION}

\begin{abstract}
The main objective of this research was to describe the mechanisms for engagement with affordances that help to sustain written interpersonal interactions of students in online discussion forums of a virtual learning environment while they were learning English as a foreign language. The notion of affordance was discussed in this study according to three dimensions: (i) environmental, (ii) technological, and (iii) linguistic, associating a pragmatic theory to the latter (GREENO, 1994; VAN LIER, 2000; LAMY \& HAMPEL, 2007). The research findings showed that the environmental and technological affordances contributed to the construction of students' presence as well as of a learning community. New forms of online interactions afforded new forms of language learning, especially by the movement of relexicalization and gap-filling.

Keywords: Affordances; Online Interaction; Language Learning; Distance Education.
\end{abstract}

\footnotetext{
"Doutora em Linguística pela Universidade Federal do Ceará e Professora adjunta do Departamento de Estudos da Língua Inglesa, suas Literaturas e Tradução da Universidade Federal do Ceará. Suas áreas de interesse incluem Ensino de línguas mediado por tecnologias digitais; formação de professores de línguas e análise de discurso crítica. E-mail: andreiaturolo@hotmail.com. ORCID: https://orcid.org/0000-0002-7469-328X.
} 


\section{Introdução}

Muito tem sido discutido sobre a validade de cursos na modalidade Educação a Distância (EaD), que ganham força com as possibilidades de interação na Internet. Para o ensino de línguas de uma maneira geral, uma das grandes vantagens da $\mathrm{EaD}$ aliada à Internet é proporcionar trocas dialógicas entre os indivíduos que interagem em situação de interlocução caracterizadas como autênticas, em uma época em que as relações humanas são definidas pela mobilidade, inclusão, integração, troca, intercâmbio e colaboração (WHITE, 2003; MOORE \& KEARSLEY, 2007).

Extensivos estudos sobre a aprendizagem de línguas mediada pelo computador salientam vantagens e limitações. Entre as vantagens, destacam-se a participação igualitária e democrática, livre escolha, autonomia, pressão psicológica e ansiedade minimizadas por um ambiente caracterizado por tempos e espaços mais relaxados e flexíveis em comparação com a sala de aula tradicional. Entre as restrições, as pesquisas apontam o sentimento de distância dos estudantes da $\mathrm{EaD}$, o modo de comunicação visual reduzido, principalmente quando a comunicação mediada por computador (CMC) é escrita, dificuldades com as tecnologias e os letramentos necessários que acarretam novas demandas que muitas vezes se impõem sobre uma cultura de aprender ainda tradicional, resultando em conflitos e desigualdades que precisam ser compreendidos (WARSCHAUER, 1997, 1998; CHAPELLE, 2003; CRYSTAL, 2001; LAMY \& HAMPEL, 2007).

Tendo em vista as várias vantagens e restrições que a aprendizagem de línguas na modalidade a distância apresenta, surgiu meu interesse em pesquisar o que oportunizava ou restringia a interação interpessoal online dos estudantes do curso de Letras-Inglês na modalidade a distância onde eu atuava como coordenadora de disciplinas. Observava que as interações dos estudantes no ambiente virtual de aprendizagem (AVA) muitas vezes pareciam descontínuas, fragmentadas e, até mesmo, não muito dialógicas em primeira vista e desejava pesquisar isso sistematicamente. Meu interesse era investigar quais aspectos presentes ou emergentes eram percebidos pelos estudantes como oportunidades para engajamento na interação e na aprendizagem da língua inglesa.

As oportunidades de ação, quando percebidas pelo aprendiz como algo útil e que pode proporcionar engajamento, vêm sendo chamadas na linguística aplicada de affordances. Nesse sentido, o conceito de affordance está relacionado ao conceito de percepção de oportunidades para agir no ambiente linguístico por meio de artefatos semióticos (VAN LIER, 2000, 2002; KRAMSCH, 2002, 2008; ZIGLIARI, 2008; PAIVA, 2010, 2011).

Com a hipótese de que a percepção de affordances está intrinsecamente relacionada ao indivíduo e ao ambiente em que interage e que, conforme este se engaja com affordances, a interação se mantém, o objetivo deste trabalho ${ }^{1}$ foi identificar e categorizar os affordances que promoviam o engajamento dos estudantes com o ambiente, com os outros e com a língua inglesa durante discussões em fóruns online. 
A fundamentação teórica desta pesquisa está ancorada nos estudos da comunicação mediada por computador, principalmente a comunicação escrita, característica do ambiente de interação pesquisado, e noção de affordance na aprendizagem de línguas. Logo depois da apresentação da teoria de base, descrevo o contexto da pesquisa e a metodologia de construção e análise de dados, as descobertas do estudo e encerro o artigo com considerações finais e conclusões.

\section{A comunicação mediada pelo computador}

A comunicação mediada pelo computador (CMC) tem características peculiares, e que vêm sendo amplamente investigadas de pontos de vista teóricos variados. Devido à natureza da interação pesquisada neste trabalho, a CMC que discuto nesta seção trata especificamente da interação interpessoal online, ou seja, indivíduos que se encontram distantes fisicamente durante a interação mediada pelo computador conectado à Internet. Por ser interpessoal e, portanto, presumidamente dialógica, muito vem sendo discutido a respeito dos processos de tomada de turno, sustentação do piso conversacional, rotinas de abertura e fechamento das conversas, negociação e manutenção do tópico da conversa, e estilo comunicacional dos participantes quanto às escolhas linguísticas e paralinguísticas de um repertório que caracteriza a CMC. Tratarei de cada um desses fenômenos separadamente e, ao final desta seção, buscarei reuni-los sob a proposta de Herring $(2004,2013 a)$ de um modelo para análise da CMC.

Tannen (2013) propõe que o discurso da interação na mídia digital seja caracterizado pela língua escrita análoga ao que já foi identificado como constituinte na conversa face a face. Propõe ainda que as mensagens e as metamensagens ${ }^{2}$ são convencionadas não apenas por formas do discurso já identificadas na interação face a face, mas também pelo que o próprio ambiente digital oferece. Nesse sentido, os discursos da nova mídia digital vêm sendo amplamente entendidos como "conversa por escrito" devido ao hibridismo entre a fala e a escrita (MARCUSCHI \& XAVIER, 2005; ARAÚJO, 2005, 2007; entre outros).

As metamensagens, conforme a definição de Tannen (2013), são construídas a partir de evidências empíricas observáveis nas mensagens na forma de pistas. Gumperz (1982) definiu pistas de contextualização como constelações de facetas presentes na superfície das mensagens pelas quais os falantes sinalizam e os ouvintes interpretam qual é a atividade, como o conteúdo semântico deve ser entendido e como cada sentença se relaciona ao que a precede e ao que a segue. As pistas de contextualização servem para canalizar as interpretações desejadas, mas nunca as determinam, entendendo que a interpretação emerge das expectativas socialmente convencionadas dos interagentes sobre a co-ocorrência entre o conteúdo e o estilo de superfície, como conhecimento presumidamente compartilhado. Por isso, devem ser sempre estudadas no processo e no contexto em que ocorrem.

A construção de pistas de contextualização em ambientes digitais sofre as restrições do meio, principalmente o número reduzido de canais da CMC escrita. Nesse contexto, emoticons e usos criativos do teclado podem ajudar a compensar 
os traços da comunicação face a face (CRYSTAL, 2001; DRESNER \& HERRING, 2010; BIESWANGER, 2013), tais como gestos, expressões faciais, alinhamentos que podem sinalizar footings (GOFFMAN, 1998) e, portanto, ajudar a construir molduras interpretativas conforme a situação social.

As pistas prosódicas da comunicação oral tais como a entoação, velocidade e ritmo da fala, altura e volume da voz, pausas, silêncios e hesitações, que sinalizam a força ilocucionária dos enunciados na interação face a face (GUMPERZ, 1982), podem ser recuperadas na CMC pelo uso criativo e não-convencional do teclado e das ferramentas de edição, tais como diferentes fontes, estilos, tamanhos e recursos tipográficos como caixa alta, negrito, itálico, que foram pesquisadas por autores como Lamy e Hampel (2007) e Herring et at. (2013) como pistas que sinalizam entoação, acento, ritmo etc. A pontuação não convencional, por exemplo, pode ajudar a construir pistas que sinalizam hesitação (...), surpresa (!!!!); palavras ou expressões em caixa alta sinalizam o volume de voz.

Outra maneira de sinalizar pistas não verbais é pela abreviação, normalmente em caixa alta, como em "LOL", que são as iniciais de laughing out loud (rindo muito alto); OMG, as iniciais de oh my god (ó meu deus), entre alguns exemplos. Tais acrônimos são muitas vezes entendidos mais como estados emotivos do que de fato uma mensagem em sentido referencial e, portanto, poderiam ser facilmente substituídos por emoticons de riso ou de surpresa, conforme os exemplos citados anteriormente. Em termos pragmáticos, tanto emoticons quanto abreviações vêm sendo interpretados em relação aos significados interpessoais que comunicam e que, portanto, colaboram na construção e manutenção do sentimento de comunidade (HERRING et al.,2013).

Outro traço da CMC que sinaliza engajamento e desejo de comunicar entre os interagentes discutido em Herring et at. (2013) é o tempo de resposta, o que também pode ser chamado de cronêmica. Tempo e ritmo de respostas têm recebido considerável atenção nos estudos da conversa como sinalizadores de significados socioafetivos por meio de pistas como pausas, hesitações, velocidade e entoação que revelam a atitude dos falantes e ouvintes sobre o tópico, sobre si mesmos e sobre os outros, contribuindo para a construção da coerência conversacional (GUMPERZ, 1982, TANNEN, 1982).

O sentimento de presença e engajamento na interação é também percebido pelo tempo de resposta entre os interlocutores que avaliam e definem a qualidade da interação e dos relacionamentos conforme a velocidade que recebem uma resposta. Walther e Tidwell (1995), por exemplo, verificaram que respostas atrasadas em sites de relacionamento tendem a levar a interação a desacelerar até o ponto de cessação, quando os interagentes percebem que os seus interlocutores não estão interessados em manter a conversa em andamento.

Herring (2013b) investigou como se dá a manutenção do piso conversacional em grupos de discussão online. Num fórum de discussão, qualquer pessoa inscrita no ambiente pode postar uma mensagem e assim tomar o turno na conversa. A mensagem, quando postada, é distribuída a todos os demais participantes da discussão, e quem a postou sustenta o piso conversacional não somente pela 
duração de tempo que os outros participantes levam para ler a mensagem, mas também pelas respostas que recebe dos demais participantes. Na interação face a face, a atenção dos demais interagentes ratificando o turno de fala e cooperando na manutenção do piso conversacional se dá por pistas gestuais e prosódicas como o direcionamento do olhar, movimentos da cabeça, expressões faciais e silêncios. Na CMC escrita, a única maneira de sabermos que o turno de fala foi ratificado pelos demais interagentes conferindo-lhe o piso conversacional é por meio das respostas enviadas que contribuem com a manutenção do tópico da conversa. Dessa maneira, a autora caracteriza o piso conversacional na interação escrita online como colaborativo.

Todos esses estudos que se debruçam sobre os fenômenos da CMC podem ser reunidos sob o que Herring (2004, 2013a) nomeia Análise do Discurso Mediado pelo Computador (ADMC). Herring vem desenvolvendo um conjunto de métodos com base na análise da conversa que ajuda a identificar padrões das estruturas e dos significados nas práticas de linguagem na CMC. Os dados desta pesquisa são analisados à luz das propostas de Herring para a ADMC, porém, não como uma moldura, mas sim adaptada à noção de affordance. Discuto isso a seguir.

\section{Affordances na aprendizagem de línguas}

A noção original de affordance reside na hipótese da percepção direta de oportunidades para agir no ambiente ecológico e isso não inclui, em princípio, um processo de significação, ou representação, num sentido semiótico (GIBSON, [1979] 1986). Porém, na linguística aplicada, a noção de affordance vem sendo tratada como um processo semiótico e, portanto, mediado simbolicamente.

Para van Lier (2000):

'affordances consistem em oportunidades para a interação conforme as coisas no meio ambiente se relacionam às capacidades sensoriomotoras do animal' (VARELA, et.al. 1991, p. 203). Em termos de aprendizagem de línguas, o ambiente é repleto de língua que proporciona oportunidade de aprendizagem ao aprendiz ativo, participante. O mundo linguístico ao qual o aprendiz tem acesso, no qual ele se engaja ativamente, é 'repleto de demandas e requisitos, oportunidades e limitações, rejeições e convites, propiciamentos e restrições - em resumo, affordances ${ }^{3}$ (VAN LIER, 2000, p. 253).

Desse ponto de vista, não se "usa" a língua, mas sim se "age" por meio dela, conforme affordances são percebidos como oportunidades para ação e engajamento. Assim, podemos inferir que aprender a língua consiste em perceber suas formas invariantes que contêm informação e que proporcionam mais ação. As formas invariantes da língua podem ser percebidas nos enunciados orais, escritos ou multimodais, como artefatos simbólicos disponíveis para que se possa agir sobre eles, interpretando-os, modificando-os e ressignificando-os continuamente. Por isso, deste ponto de vista, aprender é estar imerso em um ambiente ecológico rico em artefatos semióticos, que são ressignificados cada vez que percebidos e tomados para ação. 
A partir de van Lier $(2000,2004)$, affordances têm sido discutidos na aprendizagem de línguas de várias maneiras, com especial interesse quando o processo ensino/aprendizagem se dá em ambientes online. Levy e Stockwell (2006), por exemplo, se referem ao conceito de affordance argumentando que existe um complexo de relações de estruturas normativas da interação conversacional que são impactadas pelos affordances ofertados pela tecnologia. Nesse sentido, affordances se relacionam às condições tecnológicas do ambiente que permitem escolhas linguísticas, tipos de mensagens que podem ser enviadas ao ambiente, tipos de relacionamentos que podem ser construídos considerando as pressões construídas na CMC conforme as condições tecnológicas do ambiente.

Godwin-Jones (2003), que investigou o design de websites para ensino/ aprendizagem de línguas, evidenciou as relações entre as ferramentas disponibilizadas nos ambientes, os métodos de ensino propostos e as ações dos usuários conforme se engajavam com e no ambiente. Discutiu affordances como um arranjo de ferramentas disponíveis, tais como links da própria página para agendas diárias, apostilas, amostras de testes, bibliografias; ferramentas de acompanhamento e avaliação da performance e participação (notas, número de acessos); links para outros sites na web com conteúdos relacionados e que podiam, por sua vez, dispor de outras ferramentas interativas, como exercícios de prática, quizzes online; ferramentas para a comunicação eletrônica como fóruns, chats e emails hospedados nos AVAs.

Os fóruns de discussão dispõem de variadas ferramentas e aplicativos conforme a plataforma em que estão hospedados. Há alguns que oferecem uma variedade de formas de visualização das listas de mensagens, por exemplo, em threads (linhas de conversa), em ordem cronológica da mensagem mais recente à mais antiga ou vice-versa, em ordem alfabética dos nomes dos participantes; alguns também oferecem a possibilidade de esconder mensagens já lidas. Algumas ferramentas são botões que permitem anexar arquivos, inserir imagens, vídeos, podcasts, etc. Entre outras ferramentas, estão o corretor ortográfico, banco de emoticons, ferramentas para edição (fontes, cores, tamanhos dos caracteres). A presença das ferramentas, e quais ferramentas, no ambiente impactam as formas linguísticas e as formas de interação de uma maneira geral conforme os usuários percebem usabilidade nelas e se engajam com elas e por meio delas. Por isso, são reconhecidas como affordances (WARSCHAUER \& KERN, 2000; GODWIN-JONES, 2003; LAMY \& HAMPEL, 2007).

Como o campo das ciências da computação e de webdesign estão em constante evolução, novas ferramentas e aplicativos surgem o tempo todo impactando novas formas de interação e usos da língua na CMC. Ao tratar dessa dinâmica, Beatty (2003), chama atenção não só para a emergência de novos affordances, mas também para os misaffordances. A autora define affordances como pistas visuais que um objeto dispõe sobre como pode ser usado e que impacta funções intencionadas ou não intencionadas pelo seu design. Dessa maneira, assim como Larsen-Freeman e Cameron (2008) salientaram, o que pode ser um affordance para um indivíduo, pode não ser percebido como algo útil por outro indivíduo. 
Rama et al. (2012), buscaram identificar quais affordances dos MMOGs (acrônimo para massively multiplayer online games, que são jogos online jogados/praticados por milhares de jogadores/pessoas) favorecem o desenvolvimento linguístico e a socialização. De uma perspectiva sociocultural da aprendizagem, os autores definiram affordances não somente como ferramentas disponíveis nos ambientes que favoreciam a interação e as produções linguísticas dos jogadores, mas também como os "próprios jogadores" agindo no ambiente. Os affordances que identificaram foram reunidos em três grupos: (i) os que promovem espaços seguros de aprendizagem para abordar aspectos da própria língua; (ii) os que enfatizam a competência comunicativa ou a habilidade de comunicar significativa e efetivamente dentro de um dado contexto, e (iii) os que promovem ações colaborativas orientadas pelos objetivos entre jogadores experts e novatos.

Segundo os autores, os affordances não estavam necessariamente pré-dispostos no ambiente, mas sim emergiam conforme as ações dos jogadores. Por exemplo, os affordances do tipo (i) eram a formação de comunidades, que promoviam espaços seguros com relações colaborativas, em que os usuários se sentiam mais à vontade para interagir, com menos ansiedade. Nomearam esses affordances como guildas (agremiações). Os affordances do tipo (ii) emergiam conforme os usuários ingressavam, ou eram aceitos em uma das guildas. Ali vivenciavam oportunidades de desenvolver a competência comunicativa conforme as normas interativas já estabelecidas naquela guilda, como as rotinas de saudações, aberturas e fechamentos das conversas, pedidos para tomada de turno etc. Os affordances do tipo (iii) foram encontrados em agrupamentos de jogadores do tipo raid (um grupo de dois ou mais jogadores que, juntos, precisam atingir algum objetivo no jogo), um espaço em que experts e novatos interagem em contextos múltiplos, e que abre oportunidades de interação entre mais e menos experientes no jogo e também na língua. Ainda que os affordances identificados pelos autores fossem os mesmos para todos os jogadores, a maneira com que os jogadores se engajavam com eles variava conforme suas personalidades, interesses, necessidades, percepções, entre outros possíveis fatores que, conforme a recomendação dos autores, merecem ser estudados.

Lamy e Hampel (2007) discutem affordances de duas perspectivas: algo que está disponível no ambiente e algo que está relacionado a fenômenos sociais, o que inclui a própria língua. Em termos de affordances disponíveis no ambiente, as autoras relacionam aplicativos e ferramentas que proporcionam formas de interação, como aspectos da navegação e da interface; a criação de artefatos e a sua manipulação; artefatos de armazenamento, de resgate e de display de informações; ferramentas para edição de textos, imagens e gráficos compartilhados; ícones clicáveis para interação; envio e recebimento de mensagens assíncronas e sincrônicas (como o fórum e o chat); ferramentas de voice-over (por exemplo, audioconferência); ferramentas de reconhecimento de voz; uso simultâneo de diferentes canais (como videoconferência). Nesse sentido, affordance pode ser entendido como uma funcionalidade tecnológica.

Ainda relacionado ao ambiente, as autoras discutem cronicidade como affordance. A interação assíncrona no ambiente é um affordance para a reflexão, 
leitura e planejamento de produções linguísticas, para a participação de aprendizes tímidos ou ansiosos, e para o uso de outros affordances como o dicionário. Já a interação sincrônica é um affordance para trocas linguísticas em tempo real e ensaio para situações face a face. $\mathrm{O}$ affordance cronêmico do fórum relacionado ao modo semiótico escrito permite atenção aumentada que promove habilidades analíticas levando o uso da língua caracterizado pela acurácia, por exemplo.

Estão presentes também restrições, que podem ser tecnológicas, como, por exemplo, alguma ferramenta, serviço ou aplicativo que estão disponíveis no ambiente mas que não funcionam bem, ou que funcionam satisfatoriamente mas que em dado momento apresentam alguma falha (queda no serviço de Internet, falha no aplicativo de sincronização de status de participação etc.); ações de linguagem problemáticas, incompletas, deslocadas, mal-compreendidas que levam a desentendimentos e perturbam o engajamento podendo cessá-lo; tempo limitado para respostas que gera pressão emocional sobre os participantes, ou tempo prolongado para respostas que gera desinteresse dos participantes para continuar a interação.

A discussão sobre restrições contextuais remonta aos estudos de Greeno (1994), anteriores a van Lier (2000). Com base em uma teoria pragmática, Greeno chama a atenção para a restrição de referência na interpretação das mensagens. A moldura interpretativa sobre um dado ambiente, que tipo de ações podem ser ali construídas, os produtos delas que ali emergem e como devem ser interpretados são restringidos pelas pistas presentes na superfície das mensagens. Estas orientam, assim como o proposto por Gumperz (1982) e discutido anteriormente, como as mensagens devem ser interpretadas; por isso, também podemos nos referir a elas como molduras para as metamensagens (TANNEN, 2013). Deste ponto de vista, as pistas de contextualização que oferecem molduras interpretativas para as mensagens e as metamensagens podem ser entendidas como affordances linguísticos.

Greeno (1994) também inclui a noção de restrição (no original constraint) como algo que proporciona um modo de reconhecer e caracterizar o affordance com facilidade. Em termos de interação verbal, a restrição para a referência é uma relação de dependência entre pelo menos duas situações: a situação na qual a sentença é enunciada e a situação sobre a qual tal enunciado convenciona informação. $\mathrm{O}$ autor entende que, se o falante e o ouvinte estiverem sintonizados (no original attuned) com um conjunto de restrições compartilhadas sobre a referência simbólica que está sendo feita, poderão fazer inferências comuns sobre essas relações.

Tendo discutido a noção de affordance de vários pontos de vista conforme identificada nos estudos apresentados nesta seção, para a análise dos dados desta pesquisa, considerarei affordances, resumidamente, como (i) artefatos tecnológicos disponíveis em um ambiente e percebidos como úteis para ação; (ii) produtos das ações construídas no ambiente que podem ser tomados como novos affordances que emergem da ação e proporcionam mais ação e engajamento, como é o caso das mensagens produzidas, ou seja, dos enunciados; (iii) o próprio ambiente, seu espaço e seu tempo, suas condições, e como os indivíduos o percebem em relação ao que deve nele acontecer. Mais adiante neste trabalho, discutirei cada 
tipo de affordance com apoio nos dados. A seguir, descrevo o contexto e os procedimentos de construção dos dados.

\section{Métodos da pesquisa}

De natureza qualitativa interpretativa, esta pesquisa foi realizada no universo do Curso de Letras-Inglês ofertado pela Universidade Federal do Ceará na modalidade a distância em parceria com a Universidade Aberta do Brasil. Este curso, que obedece ao decreto No. 5.622 de 19/12/2005, estabelece como obrigatória a carga horária de $20 \%$ em atividades presenciais e $80 \%$ desenvolvida a distância.

O projeto pedagógico do curso (UFC-VIRTUAL, 2013) considera a interação como elemento fundamental no processo ensino-aprendizagem, que pressupõe trocas dialógicas entre professores, tutores e estudantes. A didática associada às disciplinas previa que os estudantes construíssem conhecimento a partir de suas próprias concepções iniciais sobre o objeto de aprendizagem e (re)formulassem suas concepções pelos questionamentos feitos pelo professor e outros estudantes, pela apropriação da linguagem e tecnologias utilizadas e pela observação das situações cotidianas ao seu redor. A avaliação da aprendizagem, conforme descrita no projeto pedagógico (UFC-VIRTUAL, 2013, p. 65), buscava dar conta da pluralidade de ações de aprendizagem propostas para o desenvolvimento das disciplinas no curso.

Os dados construídos para esta pesquisa foram provenientes dos registros das interações realizadas nos fóruns de discussão online da disciplina Língua Inglesa V-B: compreensão e produção escrita. Sua ementa estabelecia estudos voltados para "situações prático-discursivas da língua inglesa, mediante estruturas léxico-gramaticais de nível intermediário-avançado para o desenvolvimento das habilidades comunicativas de ler e escrever, através dos aspectos socioculturais e interculturais das comunidades falantes desta língua e introdução aos princípios de investigação de diferentes gêneros textuais" (UFC-VIRTUAL, 2013, p. 57).

O recorte submetido para análise nesta pesquisa consiste de dez fóruns de discussão online em que participaram vinte e três estudantes e dois tutores. Os critérios empregados para a seleção deste corpus foram o número de estudantes na turma e o cumprimento das propostas de atividades: selecionei as turmas de, no mínimo, dez estudantes que tivessem realizado todas as tarefas propostas na disciplina. A expectativa ao empregar esses critérios era a de poder coletar threads (linhas de conversa nos fóruns) mais robustas. O corpus deste recorte é composto por 619 (seiscentas e dezenove) mensagens de 59 (cinquenta e nove) threads. Foram descartadas mensagens que não receberam respostas e que, portanto, não produziram conversas. A partir da identificação de padrões preferidos de interação, foi possível a identificação dos affordances, à luz da fundamentação teórica apresentada.

Em um segundo momento, com o objetivo de identificar as percepções que os participantes dos fóruns analisados tinham de si mesmos, da atividade em andamento e das possibilidades de ação durante a interação construída no ambiente virtual de aprendizagem e, assim, investigar a percepção dos affordances identificados na etapa da análise da interação nos fóruns, foram conduzidas entrevistas 
estimuladas por dados que seguiram um roteiro semi-estruturado. Estas foram registradas em áudio e transcritas integralmente. As entrevistas foram realizadas no modo presencial, em 2015, pela pesquisadora com oito estudantes selecionados a partir da sua participação nos fóruns.

A seguir, apresento os resultados obtidos a partir de uma análise sistemática com base na ADMC, evidenciando as descobertas mais salientes dentro da tipologia de affordances anteriormente apresentada.

\section{Resultados e discussão}

Começo esta seção descrevendo brevemente a caracterização de cada tipo de affordance identificado na análise das interações nos fóruns. Logo após, trago dois excertos de dados analisados que reúnem vários desses affordances e os discuto à luz da teoria que embasa esta pesquisa. Por fim, trago excertos de entrevistas que ilustram a percepção dos affordances identificados na análise das interações nos fóruns. Os affordances identificados foram caracterizados da seguinte maneira:

a) affordances ambientais: relacionados principalmente ao tempo e ao espaço conforme os interagentes percebiam a flexibilidade do tempo para reflexão, planejamento, edição e envio de mensagens; a natureza democrática do ambiente; a presença dos outros colegas no ambiente; e o desenho da tarefa (avaliativa).

b) affordances tecnológicos: o material didático disponibilizado no ambiente; os recursos digitais disponíveis na interface do fórum; o endentamento das mensagens em threads; as ferramentas de edição de texto; e o banco de emoticons foram os affordances com os quais os interagentes se engajaram ativamente.

c) affordances linguísticos: (i) na estrutura micro, os affordances com os quais os interagentes se engajaram consistiam, resumidamente, em pistas da CMC (pontuação repetida, emoticons, uso criativo do teclado, ferramentas de edição); (ii) no nível do significado, destacou-se a relexicalização (escolha vocabular ao longo das trocas de mensagens) e o preenchimento de lacunas de informação nas mensagens uns dos outros; e (iii) no nível do gerenciamento da interação, destacaram-se os rituais conversacionais (cumprimentos e saudações, abertura e fechamento de conversas); a referência aos interagentes pela marcação e solicitação de presença; e a modalização que atenuava atos de fala que ameaçavam a face.

No excerto 1 abaixo, pode-se verificar que a natureza assíncrona dos fóruns foi um importante affordance que possibilitou o engajamento com outros affordances em todos os momentos das trajetórias das interações, permitindo aos estudantes tempo para leitura, estudo e elaboração de suas mensagens (vemos que a mensagem inicial de SC4, enviada ao fórum às 00:52 do dia 07/04, obteve respostas ao longo do dia, sendo a última resposta enviada às 22:22). A assincronicidade também minimizou o impacto restritivo de eventuais falhas tecnológicas não sendo, portanto, possível, em momento algum, identificar alguma restrição tecnológica, como problemas de serviço de Internet. A mensagem inicial de SC4 respondia à pergunta proposta para discussão no fórum: What is a review?, identificado aqui como o principal affordance para esta ação de SC4. É também importante informar 
que o desenho da tarefa, avaliativa e mandatória para a formação da nota do estudante, foi também um importante affordance ambiental que impulsionou o engajamento de SC4, assim como dos demais estudantes da turma, já que propiciou o número de mensagens nos fóruns mencionado anteriormente.

Excerto 1: Fórum Aula 2 - Thread $12^{4}$

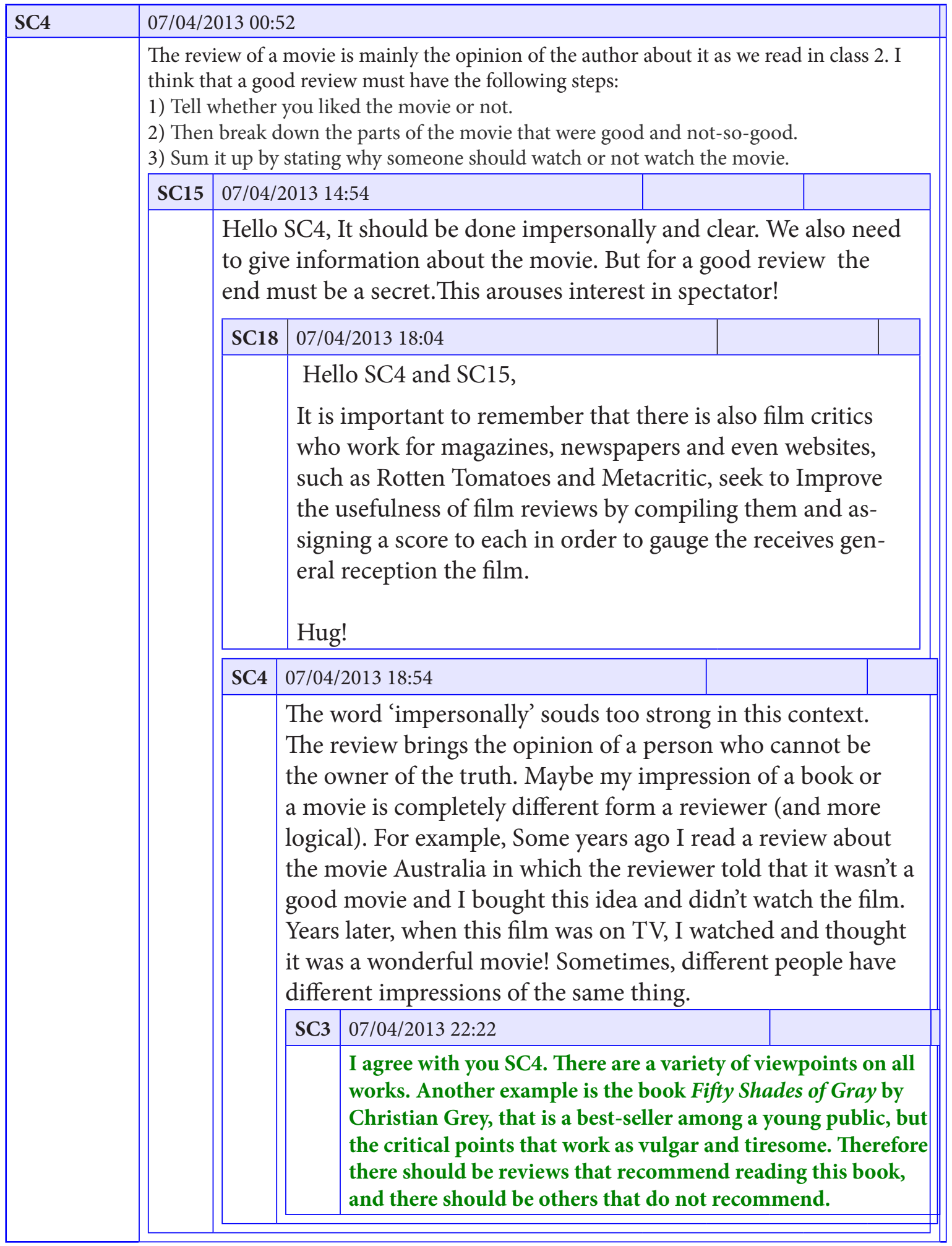


No excerto 1, a linguagem do post inicial de SC4, apesar de conter uma marcação de subjetividade ("eu acho que...") é predominantemente objetiva em terceira pessoa "uma resenha de cinema é principalmente a opinião do autor sobre o filme, conforme nos lemos na aula 2. Eu acho que uma boa resenha deve ter os seguintes passos (...)", e não cumpre as rotinas de abertura, fechamento e endereçamento aos demais colegas da turma, o que marcaria a presença dos interagentes no ambiente. Por essas razões, o post de SC4 não parece, em princípio, oferecer muitos affordances para engajamento.

No entanto, cerca de quatorze horas depois, SC15 comenta a mensagem de SC4 cumprindo rotinas de abertura da mensagem por meio de cumprimentos e endereçamento ao colega pelo nome próprio, ratificando-o diretamente, além de enviar seu comentário endentado no post, formando o thread conforme os affordances tecnológicos do software. Em seu comentário, SC15 cumpre a função de adicionar informações ("deve ser impessoal e claro, nós também precisamos dar informações sobre o filme, mas numa boa resenha o final deve ser segredo. Isso desperta interesse no espectador!"). Vemos o uso do pronome "nós" acionando intersubjetividade e foco em conjunto, além das marcas de exclamação. O comentário de SC15 é predominantemente intersubjetivo e engajador, mas o que parece ter sido o affordance principal para o engajamento de SC15 foi uma lacuna de informação deixada na mensagem de SC4, que SC15 completou com as informações adicionais inseridas com os marcadores "também" e "mas" ("nós também precisamos", "mas numa boa resenha").

Cerca de quatro horas após o comentário de SC15, outro estudante, SC18, envia uma mensagem comentando ambas as mensagens anteriores, endereçando-lhes pelos nomes próprios e pela mensagem endentada; cumprimenta os colegas com pontuação exclamativa na abertura e no fechamento de sua mensagem que também traz adição de mais informação, marcada pela estrutura "é importante lembrar que...", o que mostra novamente o engajamento pela percepção de uma lacuna de informação entre o post inicial de SC4, o comentário de SC15 e o comentário de SC18.

SC4 retorna ao thread para responder às respostas recebidas. Nesse caso vemos que ele discorda dos comentários dos colegas ao afirmar que "a palavra impessoalmente soa muito forte neste contexto", e desaprova algumas das informações adicionais sugeridas. SC4 justifica sua opinião ("a resenha traz a opinião de uma pessoa que não pode ser o dono da verdade") por meio de várias estratégias de proteção de face: (i) ele não direciona a mensagem para os colegas por meio de endereçamento pelo nome próprio, apenas endenta a mensagem ali como comentário subsequente no thread, uma maneira de não identificá-los verbalmente, protegendo-lhes a face; (ii) lança mão de modalizadores do discurso tais como, "talvez a minha impressão", "às vezes", o que atenua a força do ato de discordar com os colegas; (iii) a pontuação exclamativa demonstrando entusiasmo na mensagem ("um filme maravilhoso!") sinaliza uma expressão positiva e amistosa; e (iv) encerra a sua mensagem com um fechamento que parece resgatar uma moral cultural ou um ditado popular: "às vezes, pessoas diferentes tem diferentes im- 
pressões sobre a mesma coisa". Por parecer uma opinião popular, SC4 assume um footing coletivo, social, o que lhe ajuda a preservar-se perante os colegas como um indivíduo que emite uma opinião pessoal que infringe a dos demais, mas sim um membro de uma coletividade.

A resposta de SC4 gera um novo comentário de outro colega, SC3, que concorda com ele explicitamente "eu concordo com você SC4", endereçando-o pelo nome próprio e justificando as suas razões para concordar com SC4: primeiro ele parafraseia o enunciado do colega por meio da relexicalização de algumas expressões referenciais: "existe uma variedade de pontos de vista sobre todos os trabalhos", onde temos os sinônimos "variedade" - "diferentes", e "impressões" - "pontos de vista". SC3 escreve: "deve haver críticos que recomendam o livro, e deve haver outros que não recomendam", que retoma a mensagem anterior de SC4: "talvez a minha impressão de um livro ou filme seja completamente diferente de um crítico (e mais lógica). Por exemplo, alguns anos atrás eu li uma resenha sobre um filme australiano na qual o crítico dizia que o filme não era bom e eu comprei a ideia e não assisti ao filme. Anos depois, quando o filme estava na televisão, eu assisti e achei um filme maravilhoso!".

Dessa maneira, verifica-se que, ainda que haja engajamento com a pergunta inicial proposta para o fórum, um affordance valioso para o engajamento interpessoal dos estudantes na conversa foi uma lacuna entre as mensagens, que poderia ser preenchida com informações adicionais em comentários subsequentes.

A percepção dessas lacunas exige dos interagentes uma leitura atenta não só das mensagens, o que revela uma fina sintonia entre eles (attunement, como propõe Greeno, 1994), mas também dos conteúdos propostos no material das aulas, assim como tempo de reflexão sobre os conteúdos que permitiram resgatar memórias de experiências prévias dos interagentes, ou resultados de estudo e observações de fatos do mundo trazidos nos seus movimentos de exemplificação.

Isso está de acordo com os princípios da $\mathrm{EaD}$ que discuti anteriormente neste artigo, de que os estudantes devem buscar relacionar a teoria e a prática durante as interações no ambiente, ancorando o que se estuda nos cursos online a experiências práticas da vida real. As lacunas, nesse sentido, se mostram como uma restrição das mensagens, conforme discutido por Greeno (1994), gerando um affordance valioso para o engajamento significativo na interação e, consequentemente, para a aprendizagem.

Os movimentos comunicativos nos comentários são, em sua maioria, de concordância ou discordância, adição de informação, e justificativa por exemplificação. A coesão e a coerência são garantids por meio de marcadores textuais, pistas modalizadoras e a relexicalização. Aberturas e fechamentos, pistas da CMC e endereçamento pelo nome ajudaram a construir significados afetivos a cada tomada de turno, marcando a presença dos estudantes no ambiente. A presença no ambiente também foi marcada pelo uso de fontes e cores diferenciadas na composição das mensagens e das assinaturas.

O thread do excerto 2 a seguir foi composto por nove mensagens. Vemos que o estudante SA4 envia um post respondendo à mesma questão proposta para 
discussão: What is a review? SA4 saúda todos os colegas e segue oferecendo respostas ("Olá, amigos. Uma revisão é um comentário de algo que nós temos a oportunidade de apreciar, seja um livro ou um filme. É uma breve descrição da história, relatando as visões de uma maneira mais indireta, objetivando fazer as pessoas se sentirem curiosas para ler um certo livro ou assistir um filme particular. É importante que a resenha seja concisa, mas que provoque curiosidade no leitor ou espectador, levando-o a descobrir o final trágico ou feliz da história."), como pode-se ler a seguir:

Excerto 2: Fórum Aula 2 - Thread 2

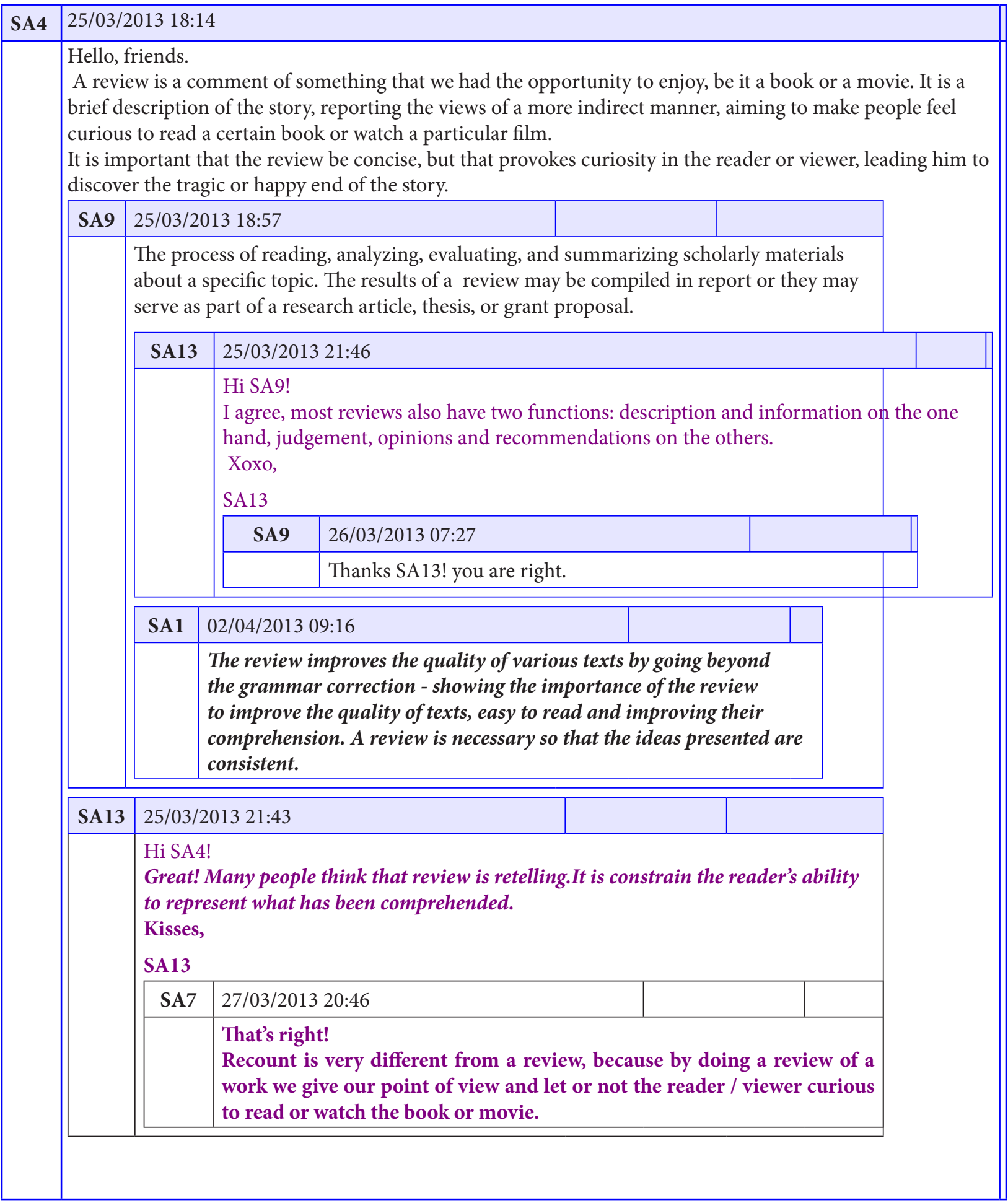




\begin{tabular}{|l|l|l||}
\hline SA7 & \begin{tabular}{l} 
27/03/2013 20:37 \\
\hline
\end{tabular} & $\begin{array}{l}\text { Exactly SA4! } \\
\text { Usually before we read a book or watch a film, which takes us to do it? We read some- } \\
\text { thing called Synopsis, which gives a sense about the subject of the book or movie, but at } \\
\text { the same time leaves us curious to know the end of this story. }\end{array}$ \\
\begin{tabular}{|l|l|} 
SA10 & $02 / 04 / 2013$ 08:49 \\
\hline & $\begin{array}{l}\text { The reviews are very important for we, students. When we need to research } \\
\text { about someone or something, soon resorted revisions. }\end{array}$ \\
\hline
\end{tabular}
\end{tabular}

No mesmo dia, cerca de trinta minutos depois do post de SA4, SA9 envia um comentário endentado ao de SA4. Porém, não indica se concorda com ele ou se discorda, se o que traz é um exemplo ou como sua mensagem deve ser entendida em relação à anterior. Tampouco sinaliza pistas afetivas ou cumpre rotinas de abertura e fechamento. Verifica-se, no entanto, a relexicalização dos termos anteriores, seja pela repetição ou por sinônimos, que pode nos levar a inferir que buscava complementar a resposta da colega com mais informações sobre o termo "review: "o processo de leitura, análise, avaliação, e resumo de materiais escolares sobre um tópico específico. Os resultados de uma revisão podem ser compilados em um tipo de relatório ou podem servir como parte de um artigo de pesquisa, tese ou grant proposal". A definição do termo "review" proposta por SA9 vai mais no sentido de "revisão de conteúdos acadêmicos", de "revisão bibliográfica ou literária". Isso foi bastante aceitável como resposta no fórum, de uma maneira geral, dada a proposta do material para a discussão, que era justamente explorar definições diferentes para a palavra "review".

Logo a seguir, outro estudante, SA13, comenta a contribuição de SA9, concordando com ele. Porém, na sua justificativa de concordância, em vez de exemplos, adiciona informações sobre a definição de "review". S13 cumpre as rotinas de saudações iniciais, endereçamento pelo nome, fechamentos com despedidas, usos criativos do teclado ("xoxo"), pontuação, assinatura, fontes e cores que personalizam sua participação com sentidos bastante afetivos e amistosos: "Oi SA9! Eu concordo, a maioria das "reviews" também tem duas funções: descrição e informação por um lado, e julgamento, opiniões e recomendações por outro. Xoxo, Sa13." SA9 agradece e concorda: "Obrigado, SA13! você está certa." Note que, em seu primeiro comentário, SA9 não havia marcado seu texto com quaisquer pistas da CMC escrita. Porém, após o investimento socioafetivo de SA13, SA9 toma a concordância como um elogio, já que responde a ele na forma de um agradecimento, formando um par adjacente "concordância-agradecimento".

O estudante SA13 também comenta o post inicial de SA4. Igualmente, inicia sua mensagem com abertura, saudações, endereçamento pelo nome, assim com o fechamento também traz saudações de despedidas bastante amistosas e informais, e a sua assinatura, o que marca fortemente a sua presença. S13 avalia a mensagem anterior com a menção "great!" (ótimo) e, logo em seguida, traz as 
justificativas para sua avaliação. Uma possível tradução pode ser: "Oi SA4! Ótimo! Muitas pessoas pensam que a resenha é uma recontagem. Isso é restringir a habilidade do leitor de representar o que foi compreendido. Beijos, SA13". Com isso, SA4 direciona a discussão para que o tópico fique centrado no aspecto de que a "review" não é um resumo ou uma recontagem. Isso mostra a rigidez e o controle do tópico de maneira coletiva; ainda que os pisos conversacionais sejam respeitados como legitimamente democráticos, vemos que é pelos comentários a eles endentados que são de fato convalidados pelos colegas e, portanto, sustentados, o que corrobora as afirmações de Herring (2013) a respeito do piso conversacional colaborativo.

Em ambas as threads aqui trazidas, verifica-se que os interagentes avaliavam as mensagens uns dos outros por meio de menções, tais como "muito bem!", "ótimo!", concordassem com eles ("concordo com você!"), adicionassem mais informações, complementando o que havia sido dito ("não podemos esquecer também (...)"), ou trouxessem exemplos, ilustrações etc. Discordavam às vezes uns com os outros, mas nunca foi observado algum problema maior nas interações como um flaming ou um bullying. Ao contrário, comentários com a função comunicativa de discordar de algum colega mostraram um intensivo trabalho de face por meio das estratégias de polidez, como discuti anteriormente.

Isso construía um ambiente seguro para a interação dos estudantes como comunidade de aprendizagem (LAVE \& WENGER, 1991). Os affordances para a construção de uma comunidade de aprendizagem e, consequentemente, do ambiente seguro, foram as pistas da CMC, favorecidas pelos affordances tecnológicos disponíveis no fórum do AVA, tais como as ferramentas para a edição de texto (que permitiram a escolha de estilos que serviram para a marcação da presença individual e coletiva dos estudantes), o banco de emoticons, além, é claro, da flexibilidade de tempo para que os interagentes pudessem lançar mão desses recursos (CHAPELLE, 2001; 2003; LEVY \& STOCKWELL, 2006; LAMY \& HAMPEL, 2007; HERRING et al.; 2013etc.).

A assincronia do ambiente parece ter sido um affordance para estudo, reflexão, elaboração e leitura das mensagens, mas, por outro lado, parece ter sido uma restrição ambiental que causou uma sensação de tempos e espaços maiores e mais distantes. O tempo, nesse sentido foi uma restrição que impulsionou a necessidade da marcação da presença no espaço. Por isso, nos termos de Greeno (1994) de que uma restrição revela o affordance, a cronêmica assíncrona foi uma restrição espaciotemporal que permitiu a emergência de affordances que sinalizavam a presença e, assim, mais engajamento. Isso pode justificar a constante marcação da presença no ambiente pela construção das pistas da CMC discutidas no parágrafo anterior e pelo endereçamento pelo nome próprio, pelos acionadores da intersubjetividade como o pronome "we" ("nós"), e pela constante marcação do "eu estou com você" por meio do "I agree with you" ("eu concordo com você").

A percepção das lacunas e preenchimento delas pelo oferecimento de mais informações nos comentários foi favorecida pelo affordance linguístico saliente: a relexicalização. A relexicalização, entendida como a repetição de vocabulário e 
expressões de um turno para o outro e que sinaliza a intersubjetividade dos interagentes (MCCARTHY, 1991), também permitia a construção do sentimento de presença. Esse foi um importante affordance para o engajamento, já que revelava a coesão dos interagentes compartilhando o foco de suas ações.

A relexicalização foi percebida pelos estudantes como algo que lhes ajudava a interagir nos fóruns. Durante a entrevista, uma das perguntas colocadas pela pesquisadora foi: "Que coisas ajudam você a participar dos fóruns em língua inglesa?". O excerto abaixo mostra a percepção da relexicalização como um affordance importante, não somente para engajamento com e no ambiente, com a língua e com o colega, mas também para a aprendizagem da língua:

Excerto 3: entrevista com SC12.

A própria mensagem dos colegas me ajudam, as expressões que eles usaram, eu pego dos colegas e utilizo, também, lá da aula, que a gente tá discutindo, uma expressão lá da aula que talvez eu nem conhecesse, tipo assim, esse ponto lá... teve uma aula que foi muito... foi a respeito do affective filter do Krashen e a gente usou bastante essa expressão, pronto, tudo, tanto dos vídeos postados nas aulas... como as próprias aulas, né? os tutores, os próprios tutores usam expressões, ai você pensa assim, gostei dessa expressão... achei interessante, nunca tinha visto, vou passar a usá-la... então isso ai ajuda muito...

Nas entrevistas, os estudantes também reconheceram o movimento de preenchimento de lacunas deixadas nas mensagens dos colegas como um importante affordance para engajamento nas interações. Os dois excertos abaixo revelam essa percepção verbalizada pelos estudantes:

Excerto 4: entrevista com SC16.

Eu procuro responder alguma coisa que... eu procuro ler o que a pessoa já disse, mas procuro dar alguma... completar alguma informação do que o aluno colocou lá (...), assim pra... de maneira geral... uma coisa que eu posso dar alguma contribuição.

Excerto 5: entrevista com SC17.

Às vezes a gente pergunta, mas é mais comum a gente acrescentar alguma coisa... Acrescentar alguma coisa do que ele disse, a gente comenta aquilo que ele falou e a gente acrescenta alguma coisa, alguma visão nossa particular, ou então alguma coisa que a gente pesquisou e escreveu ali no fórum.

A seguir, extraio algumas conclusões deste estudo e deixo algumas considerações finais e conclusões.

\section{Considerações finais}

Entre as descobertas mais relevantes, identificou-se que a cronêmica assíncrona foi um affordance que proporcionou mais tempo de leitura, estudo, planejamento e edição de mensagens, e usos mais complexos da linguagem. Porém, por outro lado, a cronêmica assíncrona foi uma restrição para a interação por 
aumentar o sentimento de distância. Isso mostrou que um mesmo aspecto do ambiente pode funcionar como affordance para determinadas ações e como restrições para outras.

A necessidade da construção da presença no ambiente se mostrou relevante como modo de compensar o sentimento de distância e propiciar mais engajamento, principalmente o engajamento social. A marcação da presença individual de formas bastante variadas, porém, todas igualmente acolhidas, contribuiu para a construção de um ambiente relaxado, seguro e colaborativo, característico de uma comunidade de aprendizagem. A presença individual e da comunidade foi construída principalmente pelos affordances tecnológicos das ferramentas de edição de texto (cores, assinaturas, usos criativos do teclado, pontuação, emoticons etc.), além de estilos individuais, endereçamento e assinaturas que marcaram as rotinas de abertura e fechamento das mensagens. A comunidade de aprendizagem, por sua vez, também funcionou como affordance para mais engajamento. A identificação de lacunas nas mensagens uns dos outros, as quais poderiam completar com mais informação, se mostrou como uma restrição das mensagens que geraram um importante affordance para engajamento nas interações. Os estudantes buscavam as mensagens com lacunas a fim de deixarem seus comentários para complementá-las, ao invés de mensagens de outros colegas que eram muito completas e que não permitiam outras contribuições. Infere-se, daí que a identificação de lacunas de informação como restrição nas mensagens evidenciaram ricos affordances linguísticos para a aprendizagem da língua, pois exigiam uma leitura cuidadosa e uma sintonia fina entre os estudantes.

Entre os affordances linguísticos, a relexicalização, entendida como a retomada das escolhas lexicais uns dos outros ao longo da conversa, sinalizou intersubjetividade e sintonia entre os participantes, além de serem reconhecidas como affordances que facilitavam a interação em língua inglesa. Isso pode ser detectado na voz dos próprios estudantes quando entrevistados e questionados acerca de seus processos ao participar dos fóruns de discussão. Por fim, durante as entrevistas, os estudantes manifestaram que a relexicalização levava à aprendizagem, o que torna possível afirmar que a relexicalização foi não somente um affordance para engajamento na interação, mas também um affordance para a aprendizagem da língua.

Os movimentos de preenchimento de lacunas na informação identificadas nas mensagens enviadas ao fórum online e de relexicalização não são muito discutidos nos estudos sobre a sala de aula como affordances para ações produtivas de aprendizagem de línguas. Porém, nesta pesquisa, revelaramse como os principais affordances que permitiam não somente mais engajamento com a língua alvo, com o ambiente e com o outro, mas também a aprendizagem da própria língua. Isso permite concluir que novas práticas de linguagem na interação online (CMC) levam a diferentes ações para a aprendizagem de línguas.

\section{Agradecimentos}

Esta pesquisa teve apoio CAPES-PDSE. 


\section{Notas}

1. Projeto de pesquisa aprovado pelo Comitê de Ética da Universidade Federal do Ceará/PROPESQ. Número do Parecer: 662.218. Data da Relatoria: 26/05/2014.

2. Metamensagens, em linhas gerais, são mensagens indiretas que servem para orientar como as intenções dos falantes devem ser entendidas, mas que não estão presentes na superfície de suas mensagens. A noção de metamensagem retoma a noção de moldura (frame) proposta por Gregory Bateson (1972, citado por TANNEN, 2013, p. 101).

3. Minha tradução. No original: "'affordances consist in the opportunities for interaction that things in the environment possess relative to the sensorimotor capacities of the animal' (VARELA, et.al. 1991, p. 203). In terms of language learning, the environment is full of language that provides opportunities for learning to the active, participating learner. The linguistic world to which the learner has access, and in which she becomes actively engaged, is 'full of demands and requirements, opportunities and limitations, rejections and invitations, enablements and constraints - in short, affordances' (SHOTTER; NEWSON, 1982, p. 34)".

4. As mensagens dos excertos que compõem este artigo foram preservadas em sua forma original.

\section{Referências}

ARAÚJO, J. C. Chat educacional: o discurso pedagógico na Internet. In: COSTA, N. B. (Org.). Práticas Discursivas: exercícios analíticos. São Paulo: Pontes, 2005, (p. 95-109).

ARAÚJO, J. (Org.). Internet e ensino: novos gêneros, outros desafios. Rio de Janeiro: Lucerna, 2007.

BEATTY, K. Teaching and Researching Computer-Assisted Language Learning. London: Pearson Education Ltd., 2003.

BIESWANGER, M. Micro-linguistic structural features of computer-mediated communication. In: HERRING, S. C.; STEIN, D.; VIRTANEN, T. (eds.). Pragmatics of Computer-Mediated Communication. Berlin: Walter de Gruyter $\mathrm{GmbH}, 2013$ (p. 463-485).

CHAPELLE, C. A. English Language Learning and Technology. Philadelphia: John Benjamins Publishing Co., 2003.

DRESNER, E. \& HERRING, S. C. Functions of the non-verbal in CMC: Emoticons and illocutionary force. In: Communication Theory. 20, 2010, (p. 249-268).

CRYSTAL, D. Language and the Internet. Cambridge: Cambridge University Press, 2001.

GIBSON, J. (1979) The Ecological Approach to Visual Perception. New York: Psychology Press, 1986.

GODWIN-JONES, R. Optimising web course design for language learners. In: FELIX, U. (ed.) Language learning online - towards best practice. Lisse, The Netherlands: Swets \& Zetlinger, 2003 (p. 43-56).

GOFFMAN, E. (1979). Footing. In: RIBEIRO, B. T. \& GARCEZ, P. M. (Orgs.) Sociolinguística interacional: antropologia, linguística e sociologia em análise do discurso. Porto Alegre: AGE, 1998 (p. 1-30).

GREENO, J. G. Gibson's affordances. In: Psychological Review. Vol. 101, N. 2, 1994 (p. 336-342).

GUMPERZ. J. J. Discourse Strategies. Cambridge: Cambridge University Press, 1982. 
HERRING, S. C. Computer-mediated discourse analysis: An approach to researching online behavior. In: BARAB, S.A.; KLING, R. \& GRAY, J. H. (Eds.) Designing for virtual communities in the service of learning. New York: Cambridge University Press, 2004 (p. 338-376).

HERRING, S. C. Discourse in web 2.0: familiar, reconfigured, and emergent. In: TANNEN, D. \& TRESTER, A.M. (Eds.) Discourse 2.0 - language and new media. Washington D.C.: Georgetown University Press, 2013 (p. 1-26). (a)

HERRING, S. C. Piso conversacional e gênero na CMC. In: SHEPHERD, T.G. \& SALIÉS, T.G. (Eds.) Linguística da internet. São Paulo: Contexto, 2013 (p. 95-124) (b)

HERRING, S. C.; STEIN, D. \& VIRTANEN, T. (eds.). Pragmatics of ComputerMediated Communication. Berlin: Walter de Gruyter GmbH, 2013.

KRAMSCH, C. (Ed.). Language acquisition and language socialization: Ecological perspectives. New York: Continuum, 2002.

KRAMSCH, C. (Ed.) Ecological perspectives on foreign language education. In: Language teaching. Vl. 41, $\mathrm{n}^{\circ} .3,2008$ (p. 389-408).

LAMY, M-N. \& HAMPEL, R. Online Communication in Language Teaching and Learning. London: Palgrave Macmillan, 2007.

LARSEN-FREEMAN, D. \& CAMERON, L. Complex Systems and Applied Linguistics. Oxford: Oxford University Press, 2008.

LAVE, J., \& WENGER, E. Situated learning: Legitimate peripheral participation. Cambridge, UK: Cambridge University Press, 1991.

LEVY, M. \& STOCKWELL, G. Call Dimensions - Options and Issues in ComputerAssisted Language Learning. New York: Lawrence Erlbaum Associates, 2006.

MCCARTHY, M. Discourse Analysis for Language Teachers. Cambridge: Cambridge University Press, 1991.

MARCUSCHI, L. A. \& XAVIER, A. C. Hipertexto e gêneros digitais. Rio de Janeiro: Lucerna, 2005. (p. 13-67).

MOORE, M. \& KEARSLEY, G. Educação a distância: uma visão integrada. São Paulo: Thomson Learning, 2007.

PAIVA, V. L. M. O. Propiciamento (affordance) e autonomia na aprendizagem de língua inglesa. In: LIMA, D. C. Aprendizagem de língua inglesa: histórias refletidas. Vitória da Conquista: Edições UESB, 2010, (p. 151-161).

PAIVA, V. L. M. O. Affordances for language learning beyond the classroom. In: BENSON, P. \& REINDERS, H. (Eds.) Beyond the language classroom. 2011, (p. 59-71).

RAMA, P. S.; BLACK, R.W.; VAN ES, E. \& WARSCHAUER, M. Affordances for second language learning in World of Warcraft. In: ReCALL, vol. 23 (03), 2012 (p. $322-338)$.

TANNEN, D. The medium is the metamessage: conversational style in new media interaction. In: TANNEN, D. \& TRESTER, A.M. (Eds.) Discourse 2.0 - language and new media. Washington D.C.: Georgetown University Press, 2013 (p. 99-118).

UFC-VIRTUAL. UNIVERSIDADE FEDERAL DO CEARA. Instituto UFC Virtual. Projeto Pedagógico do Curso de Letras: Língua Inglesa e suas Literaturas na Modalidade a Distância. Fortaleza: UFC, 2013. Disponível em: <http:// semipresencial.virtual.ufc.br/images/noticiasingles/projetopedagogicoletrasin glesead.pdf $>$ acesso em 14 de abril de 2015. 
VAN LIER, L. From Input to affordance: social-interactive learning from an ecological perspective. In: LANTOLF, J.P. (ed.). Sociocultural theory and second language learning. Oxford: OUP, 2000 (p. 145-259).

VAN LIER, L. An ecological-semiotic perspective on language and linguistics. In: KRAMSCH, C. (ed.) Language acquisition and language socialization: Ecological perspectives. New York: Continuum, 2002 (p. 140-164).

VAN LIER, L. The ecology and semiotics of language learning: a sociocultural perspective. Norwell, Mass.: Kluwer Academic Publishers, 2004.

WALTHER, J. B. \& TIDWELL, L. C. Nonverbal cues in computer-mediated communication, and the effects of chronemics on relational communication. In: Journal of Organizational Computing. 5 (4), 1995 (p. 355-378).

WARSCHAUER, M. Computer-mediated collaborative learning: theory and practice. In: The modern language journal. Vl. 81, 1997 (p. 470-481).

WARSCHAUER, M. Researching technology in TESOL: Determinist, instrumental, and critical approaches. In: TESOL quarterly. Vl. 32, 1998 (p. 757-761).

WARSCHAUER, M. \& KERN, R. Theory and Practice of Network-based Language Teaching. In: WARSCHAUER, M. \& KERN, R. (eds.). Network-based Language Teaching: Concepts and Practice. Cambridge: Cambridge University Press, 2000 (p. 1-19).

WHITE, C. Language learning in distance education. Cambridge: Cambridge University Press, 2003.

ZIGLIARI, L. Affordance and Second Language Acquisition. In: European journal of scientific research. Vl. 23, nº. 3, 2008 (p. 373-379).

Recebido em: 23/07/2019

Aceito em: 29/11/2019 